\title{
Campanha de esclarecimento: riscos de contaminação pessoal, em pequenas minerações, por minérios radioativos - urânio e tório
}

\author{
Valéria F. S. Pastura (CNEN) \\ Thomas F. C. Campos (LARANA/UFRN)
}

\section{Resumo}

A atividade de pequena mineração no Brasil é sazonal e fragmentada, é um trabalho intensivo que não apresenta mecanização, possui baixo padrão de segurança e saúde e normalmente a mão de obra não possui formação adequada. Em determinadas regiões brasileiras, ocorre a extração de minerais com minérios radioativos associados. Desta forma, para o pequeno minerador, além dos riscos inerentes da atividade, podem ocorrer riscos adicionais à sua saúde, pois no minério extraído podem estar presentes elementos radioativos.

$\mathrm{Na}$ crosta terrestre, os radionuclídeos, urânio e tório, constituem a maior fonte natural de material radioativo e são encontrados associados a cerca de 100 espécies minerais como constituinte principal, além de outros minerais em pequenas proporções. Entre os comerciáveis podemos citar: tantalita/columbita, granitos com cassiterita, carvão mineral, fosfatos, zirconita e terras raras.

Neste contexto apresentado, o presente trabalho tem por objetivo apresentar a Campanha de Esclarecimento desenvolvida nas pequenas minerações, orientando quanto aos cuidados que devem ser tomados na exploração, estocagem e transporte de minérios, alertando sobre o possível risco de contaminação pessoal e ensinando os meios básicos de proteção para evitar prejuízos à saúde.

Palavras-chave: mineração, urânio, segurança radiológica, campanha de esclarecimento

\begin{abstract}
The small mining activity in Brazil is seasonal and fragmented, is an intensive job that has no mechanization, has low standard of safety and health and usually the manpower does not have proper training. In certain regions of Brazil, the extraction of minerals is associated with radioactive minerals, thus, for the small mining beyond the inherent risks of the activity, there may be additional risks to their health, as the extracted ore may be present radioactive elements. In the earth's crust, radionuclides, uranium and thorium, are the largest natural source of radioactive material and are found associated with about 100 mineral species as the main constituent, and other minerals in small proportions. Among the tradable include: tantalite / columbite, granite with cassiterite, coal, phosphates, zircon and rare earths. This study aims to present the Enlightenment Campaign developed in small mines, guiding about the care that must be taken in the exploration, storage and transportation of minerals, warning of the possible risk of personal contamination and teaching basic means of protection to prevent damage to health.
\end{abstract}

Keywords: mining, uranium, radiation safety, education campaign 


\section{Introdução}

A Comissão Nacional de Energia Nuclear/CNEN estabelece os requisitos de segurança e proteção radiológica de instalações minero-industriais que manipulam, processam, bem como armazenam minérios, escórias e/ou rejeitos contendo radionuclídeos das séries naturais do urânio e tório que possam causar exposições indevidas aos trabalhadores, público e meio ambiente, através da realização de inspeções e auditorias regulares (Ref. Norma 4.01/CNEN).

A CNEN também fiscaliza atividades que "envolvam exposição a fontes naturais cujo controle seja necessário" (Norma 3.01/CNEN), e, como na crosta terrestre, há os radionuclídeos, urânio e tório, que constituem a maior fonte de material radioativo presente nas rochas de certos minerais, como, por exemplo, na tantalita/columbita, granitos com cassiterita, carvão mineral, fosfatos, zirconita, terras raras, etc. Em determinadas situações, tornam-se necessárias mais investigações.

No Brasil, a atividade da pequena mineração é consequência de características próprias, dada ao aproveitamento das ocorrências dispersas de determinadas sustâncias minerais em corpos descontinuados. Nesta atividade, é inviável a realização de trabalhos prévios de pesquisa, consequentemente, a instalação de empreendimentos mineiros. Como ocupa um espaço importante na economia dos municípios, o governo está tentando desenvolver iniciativas políticas propondo dotar status de empresas de mineração às cooperativas, definindo e normatizando as condições e regras para funcionamento.

Em determinadas localidades, a incidência de minérios com altos teores de urânio e tório vem despertando atenção especial da CNEN, como na Serra da Borborema, nos pegmatitos da região do Seridó, entre o Rio Grande do Norte e a Paraíba, onde o urânio é encontrado disperso nos corpos pegmatíticos e no Amapá, numa região de selva amazônica, onde estava sendo extraído minério de torianita, ilegalmente (Campos et al., 2009; 2013a).

Além dos riscos de acidentes de trabalho, inerentes às atividades da pequena mineração, somam-se os riscos radiológicos, demonstrando a necessidade de adoção de medidas e ações, voltadas para a saúde e segurança dos pequenos mineradores e da população em geral.

A possibilidade de exposição à radiação e contaminação interna por inalação de particulado é grande, pois os mineradores não possuem conhecimento dos perigos e nem utilizam equipamentos de proteção. Eles ainda manipulam minérios contendo os radionuclídeos sem depois lavar as mãos quando estão comendo ou mesmo fumando, tomam banho em locais que contêm minérios radioativos e outras situações que podem oferecer riscos de contaminação por ingestão.

Pelos motivos expostos, foi proposta e elaborada a campanha de esclarecimento denominada: Riscos de contaminação pessoal nas pequenas minerações por minérios radioativos - urânio e tório, que, desde o ano de 2004, vem orientando os pequenos mineradores sobre os cuidados básicos que devem ser tomados na exploração, estocagem e transporte de minérios contendo material radioativo.

\section{Os radionuclídeos naturais e os riscos potenciais}

Em Proteção Radiológica, denomina-se radiação de fundo (background) como sendo a soma de toda a forma de radiação natural ou artificial que é encontrada no meio ambiente e que não pode ser removida. Assim, a presença de substâncias radioativas em determinados minérios que estão sendo estocados de forma indevida pode provocar alterações significativas nos níveis de radiação de fundo de determinados ambientes de trabalho, no caso, as pequenas minerações.

Encontram-se vestígios de urânio e tório em quase todas as rochas sedimentares da crosta terrestre, embora não sejam muito abundantes em depósitos concentrados (o tório é uma exceção, no Amapá). 
São elementos-pai de cadeias de decaimento, e entre os descendentes destas séries radioativas podemos destacar o gás radônio $\left(\mathrm{Rn}^{222}\right)$ e seus produtos de decaimento radioativo (polônio- $\mathrm{Po}^{218}$, chumbo- $\mathrm{Pb}^{214}$, bismuto- $\mathrm{Bi}^{214}$ e polônio- $\left.\mathrm{Po}^{214}\right)$, os quais por si só são responsáveis por mais de $50 \%$ da radiação natural média anual. Tanto o urânio como o tório ao decaírem, emitem partículas alfa ( $\alpha$ ), que não têm grande alcance no ar $(2$ a $8 \mathrm{~cm})$, porém o risco maior de contaminação está na ingestão, adsorção pela pele ou inalação.

O comportamento do urânio tende a ser altamente móvel perto da superfície da rocha, enquanto o tório é um elemento inerte. Assim, o urânio pode ser facilmente oxidado na forma de solução aquosa e ser removido através do processo de lixiviação e redepositado em sedimentos longe da rocha de origem, podendo contaminar lençóis freáticos. Por outro lado, o tório, que é relativamente estável e bem menos solúvel que o urânio, não apresenta uma fácil mobilidade, a não ser por meios mecânicos, como o vento ou pelo processo de erosão (Campos et al., 2013b).

O radônio é um componente natural do ar que respiramos e serão seus descendentes que irradiarão os tecidos pulmonares caso o gás seja inalado. Como é transportável pela água, sua incorporação pode contribuir no aumento do valor médio da dose efetiva anual originada por fontes naturais que é de $2,4 \mathrm{mSv} /$ ano (Campos et al., 2013b), seja por ingestão que se traduziria na exposição do sistema digestivo ou por inalação, já que o gás se liberta da água e irradia os pulmões.

Em termos de saúde humana, podemos afirmar que os radionuclídeos naturais quando inalados e/ou ingeridos são distribuídos entre os órgãos, de acordo com o metabolismo e com a sensibilidade diferenciada que os órgãos possuem em relação aos diferentes tipos de radiação (soma-se ao risco radiológico, o risco oferecido pela toxicidade do urânio e do tório).

Desta forma, o dano dependerá de vários fatores, alguns dos quais relacionados com o próprio metabolismo. Por exemplo, os compostos "solúveis" ou "transportáveis" de urânio ao depositarem-se nos pulmões passam rapidamente para a corrente sanguínea, não obstante dados metabólicos evidenciarem que uma proporção elevada da fração que vai para a corrente sanguínea seja excretada rapidamente pela urina, o que não impede, contudo, que quantidades significativas fiquem no organismo e que sejam depositadas nos rins, e até mesmo nos ossos, aumentando a acumulação de radiação no organismo.

É importante salientar que os efeitos da radiação são dependentes da dose e do tipo de radiação que o ser humano recebe. Os riscos devidos a minérios radioativos traduzem-se em baixas doses, são efeitos estocásticos, ou seja, aumentando a dose, aumenta a probabilidade de efeitos tardios, como é o caso do câncer pulmonar, e não a severidade do dano.

\section{A Campanha}

Para tentar remediar danos futuros à saúde dos pequenos mineradores e da população em geral, vem sendo implantada no País, desde o ano de 2004, a Campanha de Esclarecimento: Riscos de Contaminação Pessoal nas Pequenas Minerações por minérios radioativos: Urânio e Tório.

Elaborada em linguagem de fácil compreensão, esclarece sobre os riscos que podem ocorrer em virtude do comportamento dos radionuclídeos e estimula a adoção de procedimentos simples para a prevenção de contaminação pessoal, bem como da contaminação de outras pessoas, orientando que a principal via de contaminação é a respiratória, através da inalação do pó contendo urânio e tório e que a disseminação desse pó, que pode ficar na roupa utilizada pelo trabalhador, é uma segunda via de contaminação.

Também é enfatizado que outro risco potencial é a inalação do gás radônio e de seus filhos de meia-vida curta, que pode ocorrer em minerações subterrâneas com ventilação deficiente ou se o minério for armazenado em local fechado. 
Ou seja, o risco potencial à saúde dos trabalhadores está diretamente ligado aos hábitos desenvolvidos nos locais de mineração, tanto os de higiene quanto os envolvidos no processo de extração, manipulação e armazenamento.

O projeto vem fortalecendo as ações relacionadas à prevenção de possíveis contaminações por minérios radioativos e, ao mesmo tempo, vem formando diversas parcerias com entidades distintas que estão atuando como multiplicadores da campanha, formando uma Rede de Educação em Segurança Radiológica.

A partir do cenário descrito, este trabalho teve como objetivos (i) localizar pequenas minerações de tantalita/columbita, granitos com cassiterita, carvão mineral, fosfatos, zirconita e terras raras com altos teores de U e Th associados; (ii) desenvolver ações de promoção à prevenção dos riscos de contaminação pessoal através da distribuição de material didático e da realização de palestras, previamente elaboradas em função do público alvo; (iii) avaliar as pequenas mineradoras nas áreas de abrangência, em especial aquelas que apresentam maiores fatores de risco, através de entrevistas e levantamentos radiométricos in situ e análise de amostras de concentrados do mineral e de água, para formular itens de segurança diversos; (iv) detectar o local de estocagem dos minérios contendo minérios radioativos e propor uma solução de armazenamento; (v) definir qual será a melhor estrutura para implantação de um sistema de controle dos minérios com altos teores e, se necessário, a implantação de um sistema de controle radiológico dos pequenos mineradores.

\section{Metodologia}

A metodologia consistiu na manutenção de uma Rede de Educação em Segurança Radiológica em que fazem parte cooperativas, sindicatos, escolas, ONGs, entidades envolvidas com a segurança nacional e outras entidades representativas, cujo objetivo é fomentar ações de segurança radiológica, garantindo a saúde do trabalhador, de seus familiares e da população como um todo, permitindo sinergia e maior eficácia dos esforços empreendidos pelos membros da rede.

Esta rede tem demonstrado ser de extrema relevância, visto que os pequenos mineradores não são trabalhadores fixos, Este tipo de exploração mineral é sazonal, dependendo do clima e de fatores econômicos, portanto, com a rede, garantimos a continuidade do trabalho através dos multiplicadores que estão sendo formados.

Sendo assim, nesta Rede de Educação em Segurança Radiológica foram propostas as seguintes ações:

- Implantação de campanha de esclarecimento em municípios cuja extração mineral envolva riscos radiológicos.

- $\quad$ Levantamento prévio dos recursos minerais potenciais dos municípios.

- Distribuição da cartilha (Figura 1), Cuidados no garimpo com os minérios radioativos: Urânio e Tório, nos locais de pequena mineração e nas cooperativas, sendo a leitura feita conjuntamente com os pequenos mineradores e seus familiares; nas escolas municipais e estaduais para alunos do Ensino Fundamental e Médio, durante palestras técnicas.

- Distribuição do cartaz (Figura 1) Cuidados no garimpo com os minérios radioativos: Urânio e Tório em pousadas, bares e outros locais de frequência dos pequenos mineradores, contendo informações sobre os cuidados básicos que devem ser tomados durante a exploração; também em bibliotecas e sindicatos, entre outros locais importantes na região.

- A utilização da cartilha e do cartaz visa, principalmente, atuar na capacidade de memorização visual, uma vez que os pequenos mineradores, em sua maioria, não possuem um grau adequado de instrução. 

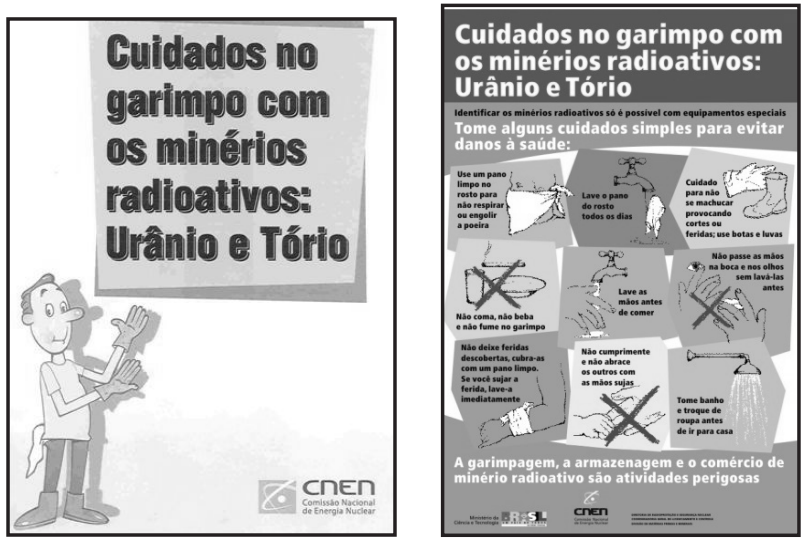

Fig. 1 - Cartilha e Cartaz

- $\quad$ Entrevistas na imprensa televisiva e escrita.

- Apresentação de palestras e seminários sobre minérios radioativos e quais os métodos de prevenção aos riscos devidos à exposição e contaminação, que são elaboradas em função do público-alvo.

- Divulgação em cooperativas de pequenos mineradores, em cooperativas de agricultores (como a atividade é sazonal, os pequenos mineradores também atuam na agricultura), entre professores de ensino fundamental e médio, alunos do ensino fundamental e médio, no sindicato de professores estaduais e municipais, na Polícia Federal Ambiental, na Polícia Militar Ambiental, Defesa Civil, Corpo de Bombeiros, Postos de Saúde Estaduais e Municipais, Secretarias de Meio Ambiente, estaduais e municipais, no Departamento Nacional de Produção Mineral/DNPM e no Instituto de Meio Ambiente e Recursos Naturais Renováveis/IBAMA.

- $\quad$ Nas escolas, as palestras têm uma linguagem simples, porém direta, com o objetivo de utilizar as crianças como agente multiplicador nas famílias, na orientação dos pais e também porque estarão adquirindo novos conhecimentos caso se tornem pequenos mineradores.

- Para os professores e alunos do Ensino Médio, as palestras são técnicas visando dar esclarecimentos sobre radioatividade natural, termos da área nuclear e são distribuídas apostilas contendo conceitos básicos de radioproteção, o CD da cartilha digitalizada e bibliografia para consulta. Normalmente são ministradas num período de 4 a 6 horas.

- Para as instituições de Segurança Nacional, de Meio Ambiente e Produção Mineral são desenvolvidos seminários de 40 horas sobre Radioproteção e Segurança Nuclear, orientando, principalmente, quanto às medidas iniciais necessárias em situações de apreensão, incidentes e/ou acidentes radiológicos envolvendo minérios radioativos (Estado do Amapá).

- Para as Instituições de Saúde também são realizados os seminários de 40 horas sobre Radioproteção e Segurança Nuclear, que se tornam de vital importância, pois, ao darmos entrevistas sobre a existência de minérios radioativos nas regiões, sempre surgem situações de pânico, em que as pessoas acreditam que a radiação chegará até a cidade implicando riscos à população. Algumas pessoas procuram os postos de saúde achando que têm sintomas provenientes da radiação. (Estado do Amapá). Desta forma, as palestras focam principalmente os efeitos biológicos da radiação.

- Coleta de amostras minerais e água nos locais de trabalho e utilização dos resultados das análises para tomada de decisões programáticas.

- $\quad$ Entrevistas com pequenos mineradores. Muitos atuam há mais de 30 anos na pequena mineração. 
- Monitoramento e avaliação constante de todos os dados coletados - análises laboratoriais, observação quanto às atitudes no trabalho, locais de depósito, entre outras, identificando os problemas e buscando soluções rápidas.

- Avaliação dessas condições de contorno para que seja possível desenvolver "procedimentos radiológicos" que deverão ser aplicados pelas cooperativas, quando a atividade da pequena mineração for legalizada pelos órgãos federais competentes.

- $\quad$ Estabelecimento de prazos mensuráveis no planejamento das parcerias, para formação dos multiplicadores, para avaliação da eficácia da campanha e término da mesma.

- $\quad$ Retorno após um ano de implantação para avaliação dos resultados

\section{Resultados}

\section{Case 1: Torianita no Amapá}

Em julho de 2004, a Polícia Federal (PF) apreendeu um contrabando de minério de torianita (890 kg), proveniente da Serra do Navio (selva amazônica, muito longe de qualquer concentração populacional), cuja análise mineral, realizada em Laboratório da CNEN, indicou que o minério possui 75\% de tório, 7,5\% de urânio e $10 \%$ de óxido de chumbo em sua composição (Figura 2). A torianita é encontrada em abundância na beira de um rio da Serra do Navio na forma de depósitos aluviais. Posteriormente, ocorreram outras apreensões e em todas elas a CNEN fez o recolhimento, e todo minério apreendido está alocado em um depósito de rejeitos radioativos da CNEN.

A torianita do Amapá apresenta alta concentração de tório, cada quilo do material chega a ter 80 gramas de urânio e 750 de tório. A taxa de dose na superfície do embalado, com $890 \mathrm{~kg}$ de torianita, corresponde a $1 \mathrm{mSv} / \mathrm{h}$. Os riscos radiológicos envolvem exposição e contaminação.

Impulsionada por este evento ficou decidido iniciar imediatamente a Campanha de Esclarecimento na cidade de Macapá.

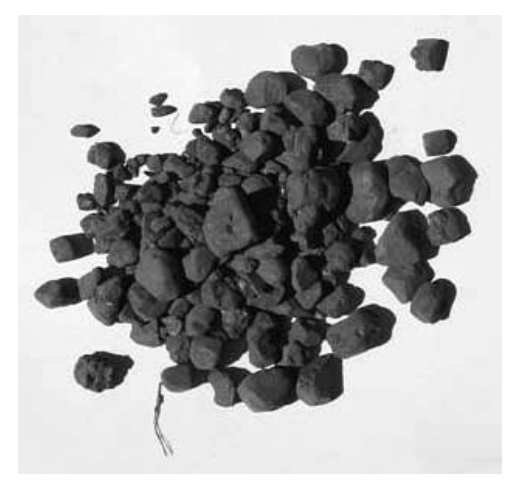

Fig. 2 - Torianita, Amapá

A primeira atuação da campanha foi através dos meios de comunicação, em que os técnicos deram entrevistas para tranquilizar a população, pois ao ser divulgada a apreensão da torianita, houve início de pânico, por algumas pessoas acharem que estavam sendo irradiados e também contaminados, já que algumas das apreensões foram feitas em residências. 
Nestas entrevistas, a equipe técnica informou que a extração de torianita apresentava riscos à saúde do minerador e de seus familiares, pelo armazenamento nas residências, mas não oferecia riscos à população em geral; também explicou que este minério é monopólio da União, sendo ilícita sua exploração e comércio.

Para os programas de televisão, a equipe optou por uma demonstração prática utilizando um detector de radiação e uma quantidade pequena de torianita para evidenciar que a dose diminui em função da distância, pois em certo momento da experiência o equipamento não mais emitia sinal sonoro demonstrando que era impossível haver algum risco à cidade, já que o depósito mineral se encontra na selva a muitos quilômetros de distância.

As seguir, foram ministradas palestras em os órgãos de segurança e de meio ambiente, envolvidos nas apreensões, orientando-os quanto aos procedimentos básicos de radioproteção (foi cedido um detector de radiação para a PF) e nas escolas, para professores e alunos (Tabela 1).

Até o final de 2005, a Campanha já foi desenvolvida em 07 (sete) municípios, todos com pequena mineração - Tartarugalzinho, Amapá, Ferreira Gomes, Pedra Branca do Amapari, Porto Grande, Serra do Navio e Calçoene.

\begin{tabular}{|l|l|}
\hline Palestras nas pequenas minerações & 04 \\
\hline Palestras em cooperativas de pequenos mineradores & 08 \\
\hline Palestras em escolas estaduais e municipais & 16 \\
\hline Palestras em sndicatos de professores & 02 \\
\hline $\begin{array}{l}\text { Seminários para entidades de segurança nacional, saúde e } \\
\text { meio ambiente }\end{array}$ & 06 \\
\hline Entrevistas aos principais jornais & 10 \\
\hline Entrevistas às redes de televisão das maiores emissoras & 06 \\
\hline
\end{tabular}

Tabela 1- Ações desenvolvidas na campanha de esclarecimento na cidade de Macapá.

Resultados referentes ao Case - Torianita no Amapá: até o presente momento foram positivos:

- Há indícios de que o tráfico ilícito diminuiu substancialmente, segundo informações da Polícia Federal, e não há mais notícias de que mineradores têm estocado minérios, como a Tantalita/Columbita, que é rica neste estado, nas residências.

- A mulher demonstrou ter um papel fundamental, pois é ela que não tem mais permitido que os minérios sejam armazenados dentro de casa, em função dos riscos à saúde dos filhos.

- $\quad$ O governo do estado se mostrou um excelente parceiro, possibilitando a realização das palestras em auditórios, fornecendo a infraestrutura necessária e apoio logístico, trabalhando na divulgação das mesmas e envolvendo as secretarias de Educação, Saúde e Meio Ambiente.

- A parceria com órgãos federais, Departamento Nacional de Produção Mineral (DNPM) e Instituto Brasileiro do Meio Ambiente e Recursos Naturais Renováveis (IBAMA), foi de extrema importância na campanha de esclarecimento.

- Nas escolas na cidade de Macapá, entre outros municípios, o tema "minérios radioativos" tem sido debatido entre professores e alunos, tendo sido apresentado em uma feira de ciências vários trabalhos com o tema Energia Nuclear e seus benefícios.

- Diversas entidades têm solicitado palestras que futuramente serão agendadas.

- A Universidade Federal do Amapá demonstrou interesse em implantar um curso de pós-graduação na área mineral, que seria desenvolvido pela CNEN, já que o estado tem um grande potencial mineral. 


\section{Case 2: Rio Grande Do Norte}

A riqueza mineral da Província Pegmatítica do Seridó-Borborema é tema recorrente na bibliografia geológica do Nordeste há mais de meio século, desde quando minerais de pegmatitos foram avidamente buscados para suprir as necessidades de tântalo, estanho, berilo e lítio, das potências aliadas da Segunda Guerra Mundial (Ref. CETEM - CT2002-040-00).

A área está compreendida entre os Estados do Rio Grande do Norte e Paraíba, abrangendo 22 municípios e apresentando uma quantidade apreciável de corpos pegmatitos (cerca de 4000), distribuídos numa área de aproximadamente $6.000 \mathrm{~km}^{2}$, cuja atividade de pequena mineração ocupa um espaço vital na economia dos municípios, pois são extraídos minerais de grande importância do ponto de vista econômico, destacando-se: berilo e água marinha, tantalita/columbita, cassiterita, ambligonita e bismutinita, além da turmalina azul, a opala, o caulim, os feldspatos, as micas e os quartzos (Figura 3).

A problemática recai no fato de que, na maioria dos locais de mineração, são encontrados corpos pegmatitos com minérios radioativos, tanto devido ao urânio disperso nos minerais citados, como pela presença de minerais primários e secundários de urânio (gumita, autunita, pitchblenda, torbenita, uraninita, entre outros) (Figura 4).

De acordo com a bibliografia existente, o total de pequenas minerações na Província está entre 400 e 800 frentes de lavras ativas. Só no Rio Grande do Norte, em pelo menos 18 localidades foram constatadas ocorrências radioativas, sendo que existem cerca de 50 frentes de lavras entre ativas e inativas nessas localidades.

As pequenas minerações, em sua grande maioria, são exploradas de forma artesanal e intermitente, e foi constatada a presença de minérios radioativos tanto de forma isolada como associados e/ou contidos na estrutura de diversos minerais.

Em função da necessidade de orientação quanto aos procedimentos a serem adotados pelos pequenos mineradores, iniciou-se a campanha de esclarecimento no ano de 2004 com a distribuição de cartazes e a realização de algumas palestras.

Primeiramente, houve o trabalho de levantamento das condições de contorno que concluiu que o risco quanto à exposição não é relevante, pois as ocorrências radioativas são pontuais e esparsas (formação de "nódulos"), sendo a contaminação interna a maior preocupação, pois, quando os mineradores, buscando extrair outros minerais e pedras preciosas destes pegmatitos, executam procedimentos evidentemente errôneos, como trabalhar em galerias com pouca ventilação e sem o devido uso de equipamentos de proteção os mineradores. Podem também inalar particulado contendo minérios radioativos, além do gás radônio.

Foram detectados outros comportamentos de risco passíveis de contaminação interna, por exemplo, (i) mineradores armazenavam amostras radioativas em locais próximos a cursos de água; (ii) consumiam água proveniente de nascentes do Pegmatito; (iii) armazenavam amostras em suas residências; (iv) utilizavam as cavas para asseio e (v) armazenavam rejeitos contendo minérios radioativos ao lado dos alojamentos. 


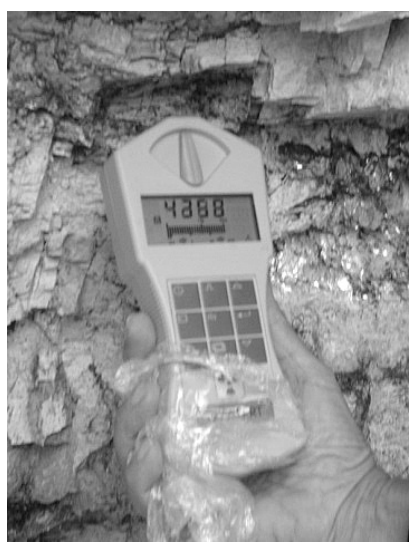

Fig. 3 - Veio de tantalita/columbita contendo urânio, coloração amarelo alaranjado, RN. Taxa de contagem 4388 cps (radiação de fundo 50 cps)

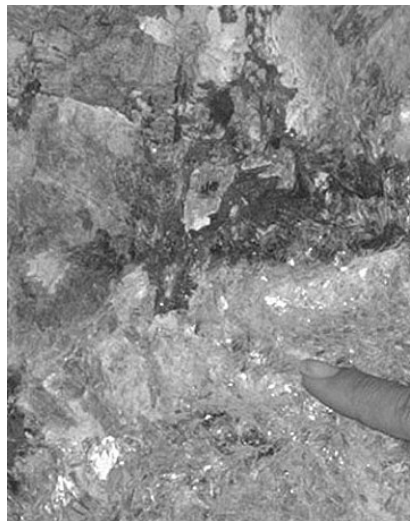

Fig. 4 - Ocorrência de uraninita no rejeito na mina do Trigueiro 1, depositado em local de banho, coloração alaranjada, RN

O trabalho de campo nesta região tem constatado que os mineradores conhecem o urânio e atribuem nomes que o identificam pela sua cor característica - amarelo; comumente eles o chamam de "loura" ou urânia, porém desconhecem os riscos envolvidos. Também são extraídos a tantalita/columbita (Figura 3), que os mineradores chamam de "buchos", com alto teor de urânio, já constatado por análises realizadas em 2004.

Palestras nas cooperativas de pequenos mineradores foram as primeiras atuações, visando orientar quanto aos riscos envolvidos e os procedimentos de prevenção à contaminação pessoal que podem ocorrer nos processos envolvidos na mineração e alertar sobre o gás radônio emitido pelo minério, pois os mineradores utilizam a água procedente do pegmatito para subsistência, e a orientação foi de que é extremamente importante fervê-la antes do consumo, não só porque evitam problemas de contaminação por bactérias, mas também porque desta forma o gás, que é solúvel na água, se evaporará o momento da ebulição. As atuações seguintes foram palestras para alunos de ensino fundamental e médio e seminários para professores e servidores da área de saúde. Foram feitas também entrevistas tanto na mídia impressa como televisiva. 


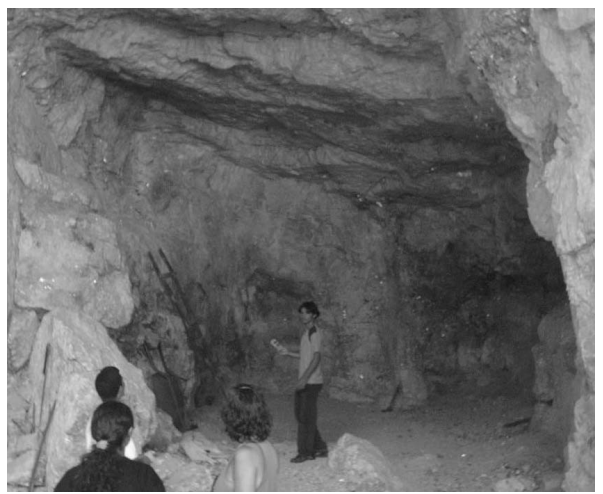

Fig. 5 - Taxa de contagem de 675cps na entrada da mina do Trigueiro 3, divisa dos estados do Rio Grande do Norte e Paraíba

As ações desenvolvidas foram:

\begin{tabular}{|l|l|}
\hline Pequenas minerações visitadas & 08 \\
\hline Palestras nas cooperativas de pequenas minerações & 06 \\
\hline Palestras em escolas estaduais e municipais & 12 \\
\hline Palestras para professores & 03 \\
\hline Entrevistas para jornais regionais & 06 \\
\hline Entrevistas na TV a cabo do município de Currais Novos & 02 \\
\hline Matéria na TV Universitária/UFRN & 01 \\
\hline
\end{tabular}

\section{Resultados}

Os resultados até o presente momento foram muito positivos:

- Ao retornar em várias mineradoras pequenas, pode-se observar que os procedimentos de prevenção de contaminação estavam sendo aplicados.

- Nos municípios visitados, a prefeitura e as cooperativas têm sido excelentes parceiras, possibilitando a realização das palestras em auditórios, fornecendo a infraestrutura necessária, trabalhando sua divulgação e envolvendo todas as instituições que podem atuar como multiplicadores.

- As amostras de minerais (albita, amazonita, quartzo, micas, tantalita e opala) provenientes de diferentes pegmatitos da região de Equador-Parelhas (RN) apresentam teores significativos de urânio e tório.

- Nas escolas, o tema "minérios radioativos" tem sido muito debatido entre professores e alunos.

- Mais uma vez, a mulher demonstrou ter um papel fundamental, pois é ela que não tem mais permitido que os minérios sejam armazenados dentro de casa, em função dos riscos à saúde dos filhos.

- $\quad$ Nas palestras ministradas em cooperativas de pequenos mineradores, são fornecidas informações sobre incidências radioativas em frentes de lavras que posteriormente são comprovadas pela equi- 
pe, como no caso de uma mina de feldspato no Estado da Paraíba, Município de Santa Luzia, onde as análises minerais constataram alto teor de tório nas amostras coletadas.

- $\quad$ Diversas entidades têm solicitado palestras que futuramente serão agendadas.

\section{Considerações Finais}

Diante dos dados recolhidos e observados podemos concluir, até este momento, que a Campanha tem sido efetiva na transmissão de informações e que as preocupações são comuns nos estados visitados:

- $\quad$ interesse despertado pelo tema é muito grande devido ao desconhecimento e preocupação com a saúde e segurança, tanto do pequeno minerador e seus familiares, como por parte da população e órgãos federais.

- A mulher demonstrou ter papel fundamental em não permitir o armazenamento em casa de minérios. Durante as palestras, elas é que mais faziam perguntas por estarem preocupadas com seus filhos e maridos.

- $\quad$ Algumas crianças nas escolas são filhos de pequenos mineradores e, durante as palestras, foi possível notar a preocupação com o pai, a ponto de dizerem que não mais deixariam que eles corressem riscos, pois iriam ler e explicar a cartilha para que os cuidados fossem tomados durante a exploração mineral.

- Durante as palestras nas cooperativas do Rio Grande do Norte, os mineradores apontam novas frentes de lavra com ocorrências radioativas e que são efetivamente constatadas pela equipe.

- A campanha deve continuar, pois o realizado até o momento é muito pouco em relação à quantidade de frentes de lavra existentes. É necessário adquirir um maior conhecimento dessas ocorrências de minérios radioativos, fazendo-se um acompanhamento periódico das pequenas minerações.

\section{Referências Bibliográficas}

Norma CNEN-NN- 3.01

Norma CNEN- NN - 4.01

CAMPOS, T. F. C.; PETTA, R. A. ; PASTURA, V. F. S. ; SINDERN, S.;

NASCIMENTO, P. S. R. . Environmental and safety education campaign on the radioactivity and the risk of malignity in the pegmatite Borborema province: preventive measures to avoid contamination with u and th. Estudos Geológicos (UFPE), v. 19, p. 77-92, 2009.

CAMPOS, TFC; PETTA, RA; MALANCA, A; PASTURA, V. F. S. ; SICHEL, SU; MOTOKI, A. O Gás Radônio E A Radiação Natural em Terrenos Metagraníticos e Pegmatíticos: O Caso do Município de Lages Pintadas (Rio Grande do Norte, Brasil). Revista de Geologia (Fortaleza), v. 26, p. 45-52, 2013a.

CAMPOS, TFC; PETTA, RA; MALANCA, A; PASTURA, V. F. S.; SICHEL, SE; MOTOKI, A. O Gás Radônio Doméstico e a Radioatividade Natural Em Terrenos Metamórficos: o Caso do Município de Lucrecia (Rio Grande do Norte, Brasil). Revista de Geologia (Fortaleza), v. 2, p. 85-93, 2013b. 